\title{
Correction Posture Tapping Meningkatkan Kemampuan Gerak Fungsional Anak Cerebral Palsy
}

\author{
Bambang Trisnowiyanto $^{1^{*}}$, Tri Budi Santoso ${ }^{2}$ \\ 1,2 Jurusan Fisioterapi, Poltekkes Kemenkes Surakarta \\ *Email: trisnowiyanto@yahoo.co.id
}

\begin{abstract}
Abstrack
Background: Cerebral palsy $(C P)$ is a collection of motor disorders caused by brain damage that occur before, during or after birth which can be caused by many factors such as, congenital, genetic, inflation, infection and poisoning during pregnancy, trauma and metabolic disorders. Children with cerebral palsy will mostly have problems with posture. Muscular spasticity found in CP children is not only found in the muscles of the limbs but also the muscles forming posture (body posture), the condition of the body shape of children with $C P$ will be exacerbated by the omission of postures that are not functional. Taping provides convenience in initiating motion, to help people with CP be able to move easily. The objectives of this study is to determine the effect of giving correction posture taping to the ability of motion of cerebral palsy children. Methods: The design in this study is a quasi experiment with a pretest and posttest design. The research will be conducted on the CP community in Yogyakarta, namely the Wahana Cerebral Palsy Family (WKCP) for 8 weeks. The research instrument used in this study was a blank check on the basic functional ability of GMFM. Results: After getting treatment in the form of Correction Posture Taping for 8 consecutive weeks, there was an increase in the functional ability of motion during sleep by 5.1385 with $P=0.000(\alpha<0.05)$, when seated by 1.0254 with $P=0.000(\alpha<0.05)$, when crawling by 0.44 with $P=0.000(\alpha<0.05)$, when standing and walking by 0.6523 with $P=0.000(\alpha<0.05)$, when crawling by 0.32 with $P=0.000(\alpha<0.05)$. Conclusion: Based on the results of research and the results of data processing, there is the effect of posture taping correction on the functional ability of children with cerebral palsy.
\end{abstract}

Keywords: cerebral palsy, correction posture, tapping, functional movement

\section{PENDAHULUAN}

Negara berkembang termasuk Indonesia, angka kejadian cerebral palsy (CP) terjadi 1 pada setiap 300 bayi lahir. Adapun jenis-jenis $\mathrm{CP}$ antara lain $\mathrm{CP}$ spastic yang ditandai dengan adanya spastisitas atau kontraksi otot yang involunter (tidak disadari) pada otot-otot tubuh dan anggota gerak, kondisi ini terjadi $70-80 \%$ kasus, dan $\mathrm{CP}$ athetoid, yang ditandai dengan pola gerakan yang tidak terkendali, lambat dan menggeliat, kondisi ini terjadi 10-20\%. CP yang ketiga yaitu ataxic yang ditandai dengan adanya gangguan keseimbangan saat duduk/berdiri dan koordinasi gerak yang terjadi sekitar 5- 10\%. CP yang keempat yaitu campuran yang merupakan gabungan atau dari jenis $\mathrm{CP}$ diatas.
Kombinasi yang umum adalah spastic dan athetoid. Bila hambatan gerak fungsional akibat $\mathrm{CP}$ tidak mendapatkan treatment yang tepat maka akan menambah berat tingkat disabilitasnya yang pada akhirnya akan mencapai tahap vegetatif (vegetatif stage) (A.T. et al., 2009; Colver et al., 2014; Graham et al., 2016; Wimalasundera \& Stevenson, 2016). Spastisitas otot yang terdapat pada anak CP tidak hanya terdapat pada otot-otot anggota gerak saja tetapi juga otot-otot pembentuk postur (sikap tubuh), kondisi bentuk tubuh anak penyandang $\mathrm{CP}$ akan diperburuk dengan adanya pembiaran posisi sikap tubuh yang tidak fungsional. Postur atau sikap tubuh akan terbentuk akibat kondisi yang habitual. Postur abnormal pada anak CP akan dipicu oleh 
adanya spastisitas yang dengan tidak sengaja dibiarkan terfasilitasi, sehingga akan menghambat gerakan-gerakan fungsional yang diharapkan akan dapat dilakukan. Sebaliknya postur atau sikap tubuh pada anak CP yang diatur secara pasif seperti dengan menggunakan taping untuk melawan pola spastisitas akan memberikan kemudahan dalam melakukan inisiasi gerak, untuk membantu penyandang CP dapat bergerak dengan mudah (Gulati \& Sondhi, 2018; Marret et al., 2013; Morgan \& McGinley, 2018; Vitrikas et al., 2020).

Perekat bersifat elastis yang dapat diaplikasikan pada kulit biasa disebut sebagai taping. Taping merupakan salah satu modalitas fisioterapi yang dapat difungsikan pada kasus CP. Taping memiliki manfaat dalam membantu kinerja otot pada saat beraktivitas, menurunkan intensitas nyeri, mengurangi bengkak, dan menurunkan spasme. Aplikasi taping juga dapat meningkatkan fungsi otot sehingga pola gerakan fungsional dapat dilakukan dengan baik (Iosa et al., 2010; Keklicek et al., 2015; Sousa Junior et al., 2017).

Metode aplikasi taping ini adalah aplikasi penempelan pita rekat pada bagian otot-otot tertentu yang mengalami spastic yang untuk menghambat (menginhibisi) kontraksi otot yang involunter atau tidak disadari. Teknik cara pemasangan taping ini diharapkan dapat dilakukan oleh para orang tua, anggota keluarga dan pengasuh anak penyandang $\mathrm{CP}$, sehingga diperlukan adanya pembelajaran atau pelatihan tentang cara memasang taping kepada orang tua, anggota keluarga dan pengasuhnya, sehingga mereka memberikan kontribusi terhadap keberhasilan treatment yang diberikan (Kaya Kara et al., 2015).

Permasalahan utama saat ini yaitu pengaruh pemberian correction posture taping dalam menghambat spastisitas otot yang di ukur dengan skala Asworth dan memudahkan anak dengan CP melakukan gerak fungsional yang akan diukur dengan menggunakan Groos Motor Functional Measurement (GMFM) belum terjawab. GMFM yang berisikan 88 item penilaian kemampuan gerak (motorik) fungsional yang meliputi dimensi berbaring dan berguling, duduk, merangkak dan berlutut, berdiri, berjalan, berlari dan melompat dapat digunakan untuk mengevaluasi kondisi tersebut (Harvey, 2017; Ko \& Kim, 2013). Tujuan penelitian yaitu untuk mengetahui efek pemberian correction posture taping terhadap gerak fungsional anak dengan cerebral palsy yang akan diukur dengan menggunakan Groos Motor Functional Measurement (GMFM).

\section{METODE PENELITIAN}

Rancangan penelitian yaitu eksperimen semu dengan rancangan pretest and postest design. Penelitian dilakukan selama 8 minggu pada tahun 2019. Penelitian dilakukan pada komunitas Wahana Keluarga Cerebral Palsy (WKCP) Yogyakarta. Informasi yang dihasilkan adalah tingkat spastisitas otot dan kemampuan gerak fungsional dasar anak penyandang CP. Jumlah sampel penelitian sejumlah 20 subjek.

Kriteria inklusi penelitian berupa pasien CP dengan usia di bawah 12 tahun, bersedia mengikuti program terapi dari awal sampai akhir, tidak mengalami gangguan sensibilitas, dan nilai GMFM minimal $50 \%$. Kriteria eksklusi penelitian berupa terdapat kelainan sendi, dan memiliki gangguan kognitif. Kriteria drop out penelitian berupa tidak menyelesaikan latihan secara penuh, dan tidak hadir di sesi evaluasi. 
Variabel dalam penelitian ini adalah pengaturan postur dan kemampuan gerak fungsional. Instrumen penelitian yang digunakan dalam penelitian ini adalah blanko pemeriksaan kemampuan gerak fungsional dasar GMFM. Terdiri dari 88 item pemeriksaan, aktifitas pada posisi berbaring dan berguling (17 item), duduk (20 item), merangkak dan kneeling (14 item), berdiri (13 item), berjalan (12 item), berlari dan melompat (12 item). Penilaian GMFM ada 4 skor yaitu $0,1,2$ dan 3 yang masing-masing mempunyai arti: (1) $0=$ tidak memiliki inisiatif, (2) $1=$ inisiatif, (3) 2 = sebagian dilengkapi, dan (4) 3 = dilengkapi (Kenyon, 2014).

Setelah data pemeriksaan telah di kumpulkan sampai dengan akhir penelitian maka data akan dianalisa dahulu. Pertama akan ditentukan skala pengukuran variabel, untuk penelitian ini skala pengukurannya adalah numerik dengan jenis penelitiannya adalah komparatif dan hubungan. Uji beda dalam kelompok digunakan paired t-test dan untuk antar kelompok digunakan independent $t$ - test. Namun jika data tidak normal, maka untuk uji beda dalam kelompok digunakan Wilcoxon test dan untuk antar kelompok digunakan Mann-Whitney test.

\section{HASIL}

Penelitian ini dilakukan pada bulan April 2017 hingga bulan Oktober 2017, yang bertujuan untuk mengetahui Pengaruh Correction Posture Taping Terhadap Kemampuan Gerak Fungsional Anak Dengan Cerebral Palsy. Subjek dalam penelitian ini adalah anak-anak penandang cerebral palsy di wilayah Bantul, Gunung Kidul, Sleman, Kalasan dan Daerah Istimewa Yogyakarta yang tergabung dalam komunitas Wahana Keluarga Cerebral Palsy (WKCP) Yogyakarta. Proses awal hingga akhir program latihan dilakukan, diperoleh subjek yang memenuhi kriteria inklusi, berjumlah total sebanyak 13 orang.

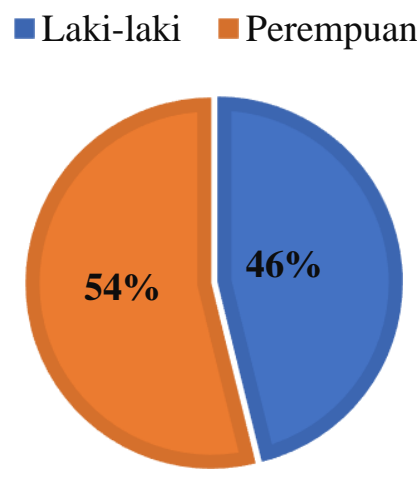

Gambar 1. Subjek Berdasarkan Jenis Kelamin

Berdasarkan jenis kelamin, subjek laki (46\%) dan 7 orang perempuan (54\%). dalam penelitian ini terdiri dari 6 orang laki- 


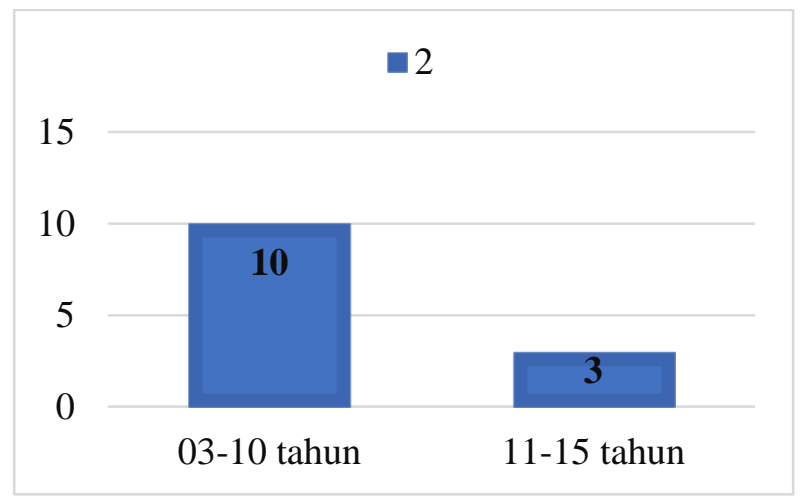

Gambar 2. Subjek Berdasarkan Usia

Subjek dalam penelitian ini 15 tahun sebanyak 10 anak (77\%) dan 11 memiliki rentang usia dari 3 tahun hingga hingga 15 tahun sebanyak 3 anak (33\%).

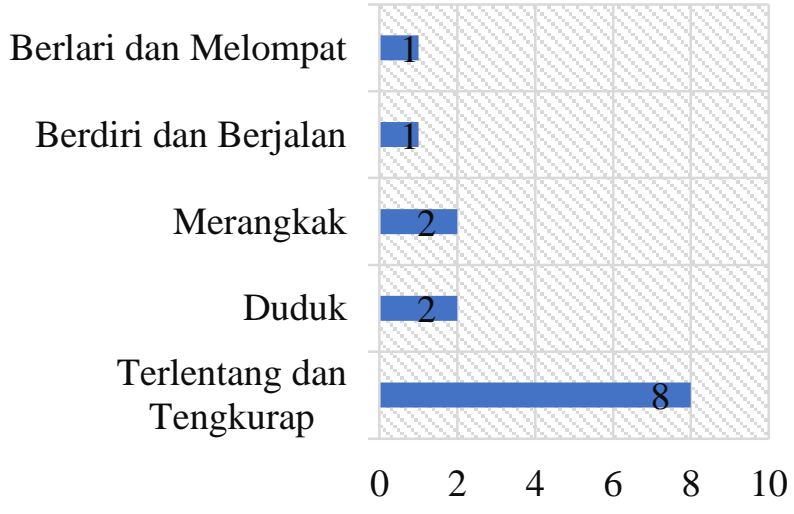

Gambar 3. Subjek Berdasarkan Tingkat Kemampuan Fungsional

Berdasarkan tingkat kemampuan Pada penelitian ini jumlah subjek fungsional yang dimiliki oleh subjek 8 kurang dari 30 orang maka diperlukan uji anak (62\%) pada level terlentang dan normalitas. Dari hasil uji normalitas data tengkurap, 2 anak (15\%) pada level duduk, dengan menggunakan Kolmogorov2 anak $(15 \%)$ pada level merangkak, 1 Smirnov test tersebut diatas, didapatkan anak (8\%) pada level berdiri dan berjalan, hasil $\mathrm{P}$ value (pre) $=0,430(\alpha>0,05)$, yang serta tidak ada satupun anak (0\%) pada berarti sebaran data dalam penelitian level berlari dan melompat. terdistribusi dengan kategori normal.

Tabel 1. Hasil Uji Beda Kemampuan Fungsional

\begin{tabular}{lcc}
\hline & $\begin{array}{c}\text { Paired } \\
\text { Samples Test }\end{array}$ & $\begin{array}{c}\text { Paired Samples } \\
\text { Correlations }(\mathbf{P})\end{array}$ \\
\hline $\begin{array}{l}\text { Pre-post fungsional gerak saat } \\
\text { terlentang/tengkurap }\end{array}$ & 5.13846 & $0.000(\alpha<0,05)$ \\
Pre-post fungsional gerak saat duduk & 1.02538 & $0.000(\alpha<0,05)$
\end{tabular}


Pre-post fungsional gerak saat merangkak

Pre-post fungsional gerak saat berdiri

Pre-post fungsional gerak saat berlari dan melompat

Pre-post fungsional gerak saat terlentang/tengkurap

Dari hasil uji analisis data dengan menggunakan One-Sample KolmogorovSmirnov Test untuk mengetahui Pengaruh Correction Posture Taping Terhadap Kemampuan Gerak Fungsional Anak Dengan Cerebral Palsy, diperoleh hasil sebagai berikut: (1) terdapat peningkatan kemampuan fungsional gerak saat terlentang/tengkurap sebesar 5.1385 dengan $\mathrm{P}=0.000(\alpha<0,05)$, (2) terdapat peningkatan kemampuan fungsional gerak saat duduk sebesar 1.0254 dengan $\mathrm{P}=0.000(\alpha<0,05),(3)$ terdapat peningkatan kemampuan fungsional gerak saat merangkak sebesar 0.44 dengan $\mathrm{P}=0.000(\alpha<0,05)$, (4) terdapat peningkatan kemampuan fungsional gerak saat berdiri dan berjalan sebesar 0.6523 dengan $\mathrm{P}=0.000(\alpha<0,05)$, dan (5) terdapat peningkatan kemampuan fungsional gerak saat berlari dan melompat sebesar 0.32 dengan $\mathrm{P}=0.000(\alpha<0,05)$.

\section{PEMBAHASAN}

Setelah mendapatkan perlakuan berupa Correction Posture Taping selama 8 minggu berturut-turut, terdapat peningkatan kemampuan fungsional gerak saat terlentang atau tengkurap sebesar 5.1385 dengan $\mathrm{P}=0.000(\alpha<0,05)$. Terdapat peningkatan kemampuan fungsional gerak saat duduk sebesar 1.0254 dengan $\mathrm{P}=0.000 \quad(\alpha<0,05)$. Terdapat peningkatan kemampuan fungsional gerak saat merangkak sebesar 0.44 dengan $\mathrm{P}=0.000 \quad(\alpha<0,05)$. Selain kemampuan tengkurap dan duduk, terdapat pula peningkatan kemampuan fungsional gerak saat berdiri dan berjalan sebesar 0.6523 dengan $\mathrm{P}=0.000(\alpha<0,05)$. Terdapat peningkatan kemampuan
0.44000
$0.000(\alpha<0,05)$
0.65231
$0.000(\alpha<0,05)$
0.32000
$0.000(\alpha<0,05)$
0.32000
$0.000(\alpha<0,05)$

fungsional gerak saat berlari dan melompat sebesar 0.32 dengan $\mathrm{P}=0.000$ $(\alpha<0,05)$.

Hasil penelitian ini sejalan dengan hasil studi "Effects of Taping The Hand in Children with Cerebral Palsy". Peneliti menyimpulkan bahwa taping dapat menjadi pilihan yang efektif untuk reposisi ibu jari dan meningkatkan fungsi ekstremitas atas dengan mengontrol ibu jari di telapak tangan secara mekanis dan memungkinkan input sensorik dengan mempertahankan posisi tangan yang benar (Keklicek et al., 2015). Penelitian lain dengan judul "Effects of Kinesiology Taping in Children with Cerebral Palsy: a Systematic Review" juga diperoleh bukti yang cukup kuat terkait efek kinesiotaping pada fungsi motorik anak dengan CP (Sousa Junior et al., 2017).

Pada sebuah kajian dengan judul "The Effects of Kinesio Taping on Body Functions and Activity in Unilateral Spastic Cerebral Palsy: A Single-Blind Randomized Controlled Trial" menyatakan bahwa kinesiotaping merupakan sebuah pendekatan tambahan yang menjanjikan untuk meningkatkan umpan balik proprioseptif dan meningkatkan kebugaran fisik, fungsi motorik kasar, dan aktivitas kehidupan sehari-hari pada anak CP (Kaya Kara et al., 2015). Efek terapeutik dari taping telah terbukti menjadi sumber daya tambahan yang menjanjikan untuk rehabilitasi konvensional pada anak-anak dengan gangguan motorik. Uji secara 
klinis telah menunjukkan peningkatan dalam kontrol postural dan aktivitas fungsional dengan kedua tungkai atas dan bawah, dan peningkatan dalam kemandirian fungsional yang dihasilkan oleh anak dengan CP (Cunha et al., 2018).

\section{KESIMPULAN DAN SARAN}

Terdapat pengaruh correction posture taping terhadap kemampuan gerak fungsional anak dengan cerebral palsy. Correction posture taping dapat digunakan untuk meningkatkan kemampuan Gerang fungsional pada anak berkebutuhan khusus. Biaya yang murah, serta tingkat keamanan yang baik membuat intervensi ini dapat diaplikasikan dalam jangka waktu yang lama.

\section{DAFTAR RUJUKAN}

A.T., P., K., V. N. B., \& M., Y.-A. (2009). Cerebral Palsy: Classification and Epidemiology. In Physical Medicine and Rehabilitation Clinics of North America.

Colver, A., Fairhurst, C., \& Pharoah, P. O. D. (2014). Cerebral palsy. The Lancet. https://doi.org/10.1016/S01406736(13)61835-8

Cunha, A. B., Lima-Alvarez, C. D. de, Rocha, A. C. P., \& Tudella, E. (2018). Effects of elastic therapeutic taping on motor function in children with motor impairments: a systematic review. In Disability and Rehabilitation. https://doi.org/10.1080/09638288.20 17.1304581

Graham, H. K., Rosenbaum, P., Paneth,
N., Dan, B., Lin, J. P., Damiano, Di. L., Becher, J. G., Gaebler-Spira, D., Colver, A., Reddihough, Di. S., Crompton, K. E., \& Lieber, R. L. (2016). Cerebral palsy. In Nature Reviews Disease Primers. https://doi.org/10.1038/nrdp.2015.82

Gulati, S., \& Sondhi, V. (2018). Cerebral Palsy: An Overview. In Indian Journal of Pediatrics. https://doi.org/10.1007/s12098-0172475-1

Harvey, A. R. (2017). The Gross Motor Function Measure (GMFM). In Journal of Physiotherapy. https://doi.org/10.1016/j.jphys.2017. 05.007

Iosa, M., Morelli, D., Nanni, M. V., Veredice, C., Marro, T., Medici, A., Paolucci, S., \& Mazzà, C. (2010). Functional taping: A promising technique for children with cerebral palsy. In Developmental Medicine and Child Neurology. https://doi.org/10.1111/j.1469-

8749.2009.03539.x

Kaya Kara, O., Atasavun Uysal, S., Turker, D., Karayazgan, S., Gunel, M. K., \& Baltaci, G. (2015). The effects of Kinesio Taping on body functions and activity in unilateral spastic cerebral palsy: A single-blind randomized controlled trial. Developmental Medicine and Child Neurology. https://doi.org/10.1111/dmcn.12583

Keklicek, H., Uygur, F., \& Yakut, Y. (2015). Effects of taping the hand in children with cerebral palsy. Journal 
of Hand Therapy. Wimalasundera, N., \& Stevenson, V. L. https://doi.org/10.1016/j.jht.2014.09. (2016). Cerebral palsy. In Practical 007 Neurology.https://doi.org/10.1136/practne urol-2015-001184

Kenyon, L. K. (2014). Gross Motor Function Measure (GMFM-66 and GMFM-88) Users' Manual,. Physical \& Occupational Therapy In Pediatrics.

https://doi.org/10.3109/01942638.20 14.931744

Ko, J., \& Kim, M. (2013). Reliability and responsiveness of the gross motor function measure-88 in children with cerebral palsy. Physical Therapy. https://doi.org/10.2522/ptj.20110374

Marret, S., Vanhulle, C., \& Laquerriere, A. (2013). Pathophysiology of cerebral palsy. In Handbook of Clinical Neurology. https://doi.org/10.1016/B978-0-44452891-9.00016-6

Morgan, P., \& McGinley, J. L. (2018). Cerebral palsy. In Handbook of Clinical Neurology. https://doi.org/10.1016/B978-0-44463916-5.00020-3

Sousa Junior, R. R. de, Lima, P. de, Silva, J. N. da, \& Vaz, D. V. (2017). Effects of kinesiology taping in children with cerebral palsy: a systematic review. Fisioterapia Em Movimento. https://doi.org/10.1590/19805918.030.s01.ar06

Vitrikas, K., Dalton, H., \& Breish, D. (2020). Cerebral palsy: An overview. In American Family Physician. 